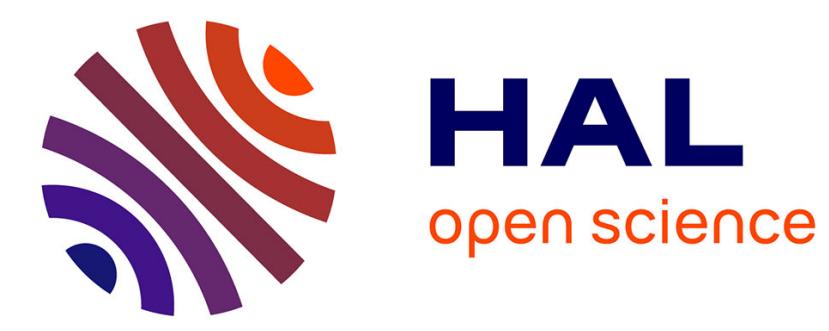

\title{
Leagility in a Triad with Multiple Decoupling Points
}

\author{
Joakim Wikner, Jenny Bäckstrand, Fredrik Tiedemann, Eva Johansson
}

\section{To cite this version:}

Joakim Wikner, Jenny Bäckstrand, Fredrik Tiedemann, Eva Johansson. Leagility in a Triad with Multiple Decoupling Points. IFIP International Conference on Advances in Production Management Systems (APMS), Sep 2015, Tokyo, Japan. pp.113-120, 10.1007/978-3-319-22756-6_14 . hal-01417410

\section{HAL Id: hal-01417410 https://hal.science/hal-01417410}

Submitted on 15 Dec 2016

HAL is a multi-disciplinary open access archive for the deposit and dissemination of scientific research documents, whether they are published or not. The documents may come from teaching and research institutions in France or abroad, or from public or private research centers.
L'archive ouverte pluridisciplinaire HAL, est destinée au dépôt et à la diffusion de documents scientifiques de niveau recherche, publiés ou non, émanant des établissements d'enseignement et de recherche français ou étrangers, des laboratoires publics ou privés. 


\title{
Leagility in a triad with multiple decoupling points
}

\author{
Joakim Wikner*, Jenny Bäckstrand, Fredrik Tiedemann, and Eva Johansson \\ Jönköping University, Jönköping, Sweden \\ \{joakim.wikner, jenny.backstrand, fredrik.tiedemann, \\ eva.johansson\}.ju.se
}

\begin{abstract}
Leagility is a strategic concept that represents a combination of lean and agile. Lean is assumed to be a cost-based strategy that is appropriate in a forecast-driven context upstream of the customer order decoupling point (CODP). Agile is the corresponding flexibility-based strategy in a customer-order-driven context downstream of the CODP. Competitive advantage is based on that the position of the CODP is aligned with the market requirements. In a dyad setting this alignment can be realized with relative ease but in a triad setting it becomes more complicated if both supply actors pursue a leagile strategy. If lean based purchasing faces an agile based delivery strategy or the opposite, where agile based purchasing faces a lean based delivery strategy, the interface is misaligned. In this paper, four interface configurations are identified and empirical examples of each are given based on a case study.
\end{abstract}

Keywords: Leagility, lean, agile, lead-time, supplier relations, decoupling points

\section{$1 \quad$ Introduction}

Lean and agile are two strategies that have attracted considerable interest in both practice and in the literature. Lean has been considered as emphasizing efficiency and how to perform a value stream in the most cost efficient way possible [1]. Ford and Toyota are seen as originators of this approach but over the years the approach has disseminated into many industries and a vast array of companies. As a reaction to this efficiency based approach, the agile strategy was suggested as an alternative that in a more explicit way embraces IT enabled virtual organizations [2]. In addition, the capability to serve individual customers was emphasized for the agile strategy and this requires a higher level of flexibility which is in contrast to the Heijunka approach to levelling that is at the core of lean. The lean and agile approaches are applicable to individual companies as well as more complex multi actor supply chains since each strategy suggests a homogenous and integrated design of all actors in the network. In the late 90's, the two strategies were combined in different ways and the most referenced is the leagile strategy that is a design employing lean and agile in tandem [3].

Employing lean and agile in tandem is manageable within a dyad setting where one company applies a leagile strategy in order to both act in a flexible way towards its customers and at the same time having a cost focus upstream. However, when it comes to a triad setting, i.e. three actors in a sequence [4] corresponding to a direct supply

* Corresponding author.

adfa, p. 1, 2011.

(C) Springer-Verlag Berlin Heidelberg 2011 
chain [5], the applications of a leagile strategy is less straight forward. There is a risk of misalignments at the interfaces between the actors in the triad due to the different strategies applied. If the companies are unaware of this complexity related to the actor interfaces, the potential advantages of employing a leagile strategy may not be realized. The purpose of this paper is thus to describe the different types of actor interfaces that can be identified when a leagility strategy is employed by the two supply actors in a triad. Consequently, the contribution is the identification of interface alignments and interface misalignments when the two consecutive supply actors act individually.

Next, leagility is investigated in the original context of a dyad and some key characteristics are outlined. Thereafter, leagility is put into a supply chain context of a triad and two types of interface alignment and two types of interface misalignment are identified. Finally, the four types of interfaces are illustrated by case examples and some ideas for further research are outlined.

\section{$2 \quad$ Leagility in a dyad context}

The concept of leagility was first defined by Naylor et al. [3] and they suggested that the decoupling point [6] is a key construct when combining lean with agile. The decoupling point is also referred to as the customer order decoupling point (CODP) by e.g. Giesberts and van der Tang [7]. A key property of the CODP was identified by Shingō [8] and was termed the P:D ratio [9] which is based on the relation between the two strategic lead-times: the cumulative Product lead-time $(\mathrm{P})$ and the requested Delivery lead-time (D). In some cases the product lead-time has been referred to as the Supply lead-time (S), see e.g. Bäckstrand and Wikner [10], to emphasize that the lead-time of all supply activities should be included, and $S$ is hence used in this paper.

These two strategic lead-times (S and D) are illustrated in Fig. 1 where the dyad with the focal actor (FA) and the customer actor (CA) is the unit of analysis. The CA requests a product with the delivery lead-time $\mathrm{D}_{\mathrm{FA}}$ from the FA and all activities at FA during the $\mathrm{D}_{\mathrm{FA}}$ are customer-order-driven. The CODP is positioned based on the $\mathrm{D}_{\mathrm{FA}}$ and differentiates activities based on forecast from activities based on customer order. The CODP is illustrated by a diamond in Fig. 1 in line with Wikner [11]. The FA has a supply lead-time $\mathrm{S}_{\mathrm{FA}}$ to supply the product to $\mathrm{CA}$ and if $\mathrm{S}_{\mathrm{FA}}>\mathrm{D}_{\mathrm{FA}}$ there is not enough time available during $\mathrm{D}_{\mathrm{FA}}$ to supply the product and hence the FA must initiate supply before the customer order is known and this is referred to as supply to forecast, which is also known as forecast-driven activities. Naylor, Naim and Berry [3] observed that the characteristics of forecast-driven activities are similar to several lean characteristics and concluded that upstream from the CODP, a lean approach is appropriate with its focus on cost efficiency through level flow in terms of volume and mix. Downstream from the CODP, the customer order is known and already in the original work on agility by Goldman and Preiss [2] it was pointed out that an agile strategy is appropriate for customer-order-driven activities where flexibility is key. This provided the third building block (in addition to CODP and lean) in the definition by leagility, see e.g. Wikner [12]. The interface between the FA and the CA is indicated by a circle in Fig. 1 and by definition this interface is balanced, i.e. the leagility applied by the FA is aligned with 
the requirements of the $\mathrm{CA}$, since the CODP is positioned based on the lead-time $\mathrm{D}_{\mathrm{FA}}$ which reflects the market requirements. In subsequent figures, an unbalanced interface is indicated with two separate ellipses.
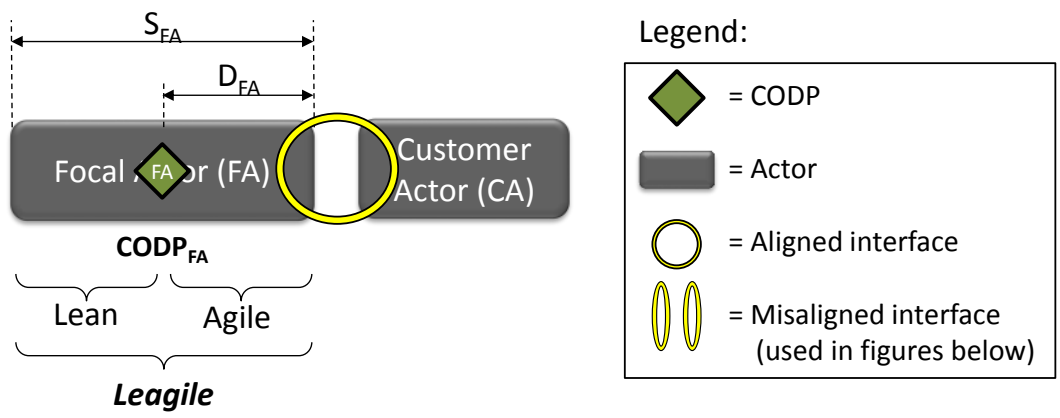

Fig. 1. Leagility in a dyad

\section{$3 \quad$ Leagility in a triad context}

The triad consists of a CA that is the final customer in the triad and the supply is represented by two actors in sequence, where the FA is responsible for supplying the CA and a supplier actor (SA) is responsible for supplying the FA. The triad context thus represents a higher level of complexity than the dyad, in the sense that there are two supply actors involved in the supply network. We investigate the impact of the CA on both the FA and the supplier of the FA (i.e. the SA) and in this context the triad is the most simple, and still relevant, supply chain structure to use. A triad is investigated to avoid unnecessary complexity and still maintain the fundamental characteristics of a supply chain. The triad has the cumulative supply lead-time of $\mathrm{S}_{\mathrm{SA}}+\mathrm{S}_{\mathrm{FA}}$. If the two supply actors (SA and FA) were integrated, they would basically correspond to one actor. But, in most cases, the integration is limited and each actor has one CODP each, which is a case of multiple decoupling points, see e.g. Sun et al. [13].

In such a fragmented triad setting it is possible to identify two configurations where there are misalignments at the interface between the SA and the FA and two configurations where the interfaces are aligned. Alignment is here defined as when the two sides of the interface between SA and FA have the same competitive priorities in terms of cost or flexibility. Alignment hence corresponds to when lean is facing lean at the interface (Fig. 2) or when agile faces agile (Fig. 4). In addition, two misalignment configurations where lean is interfaced with agile are identified, see Fig. 3 and Fig. 5.

\subsection{Leagility in a triad: Interface alignment 1}

The first configuration is when the FA purchases materials based on forecast and the SA is forecast-driven and delivers from stock. This means that at the interface both the SA and the FA are lean-oriented and cost focus hence meets cost focus. This configuration is referred to as interface alignment 1 and is illustrated in Fig. 2 where the CODP 
of the FA $\left(\mathrm{CODP}_{\mathrm{FA}}\right)$ is positioned internal to the FA. This corresponds to that all activities except purchasing can be customer-order-driven and hence the delivery lead-time is shorter than the supply lead-time of the FA $\left(\mathrm{S}_{\mathrm{FA}}>\mathrm{D}_{\mathrm{FA}}\right)$. The $\mathrm{SA}$ is forecast-driven with the CODP $\left(\mathrm{CODP}_{\mathrm{SA}}\right)$ positioned at the end of the SA and it delivers from stock. The delivery lead-time to FA from the $\mathrm{SA}$ is here assumed to be zero $\left(\mathrm{D}_{\mathrm{SA}}=0\right)$.

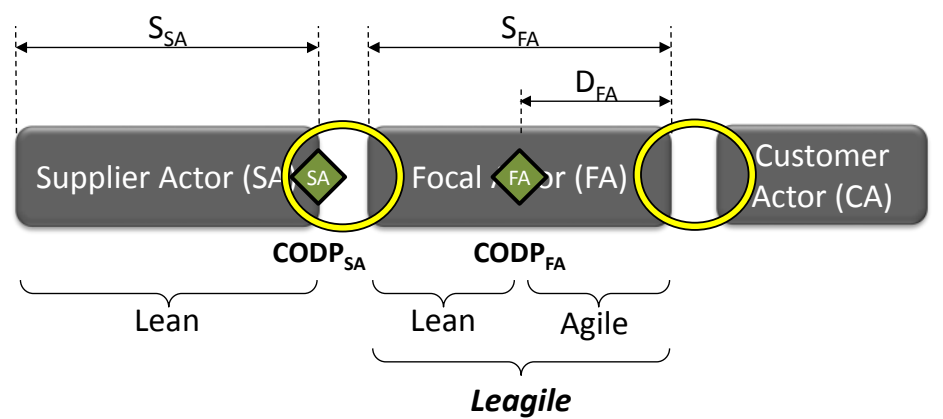

Fig. 2. Interface alignment 1: Cost-Cost

\subsection{Leagility in a triad: Interface misalignment 1}

In the configuration alignment 1 , above, the $\mathrm{CODP}_{\mathrm{SA}}$ is positioned at the end of the SA. In the configuration in Fig. 3 the CODP $_{\mathrm{SA}}$ is instead positioned upstream from the FA interface (i.e. $D_{\mathrm{SA}}>0$ ). Still, the FA is purchasing based on a forecast of future orders from the $C A$, i.e. purchasing to stock (i.e. $S_{\mathrm{FA}}>\mathrm{D}_{\mathrm{FA}}$ ). However, the $\mathrm{SA}$ performs its last activities as customer-order-driven, which means that at the interface the SA is agility oriented but the FA is lean oriented. This is referred to as interface misalignment 1 where flexibility focus meets cost focus and indicated with two ellipses in Fig. 3.
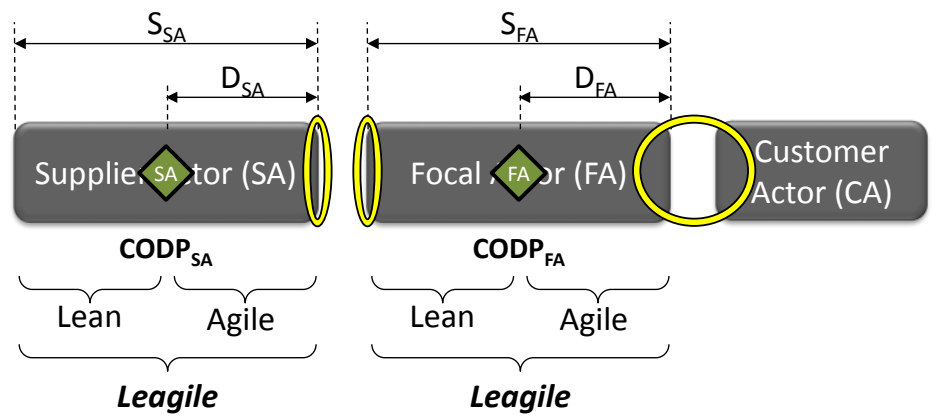

Fig. 3. Interface misalignment 1: Flexibility-Cost

\subsection{Leagility in a triad: Interface alignment 2}

The second configuration with alignment is when the FA is purchasing based on customer order from the $\mathrm{CA}$ (i.e. purchase to order, $\mathrm{S}_{\mathrm{FA}} \leq \mathrm{D}_{\mathrm{FA}}$ ) and the $\mathrm{SA}$ is performing 
some activities based on customer order from the FA (i.e. $\mathrm{D}_{\mathrm{SA}}>0$ ). Both sides of the interface between SA and FA are thus agility oriented with flexibility focus, see Fig. 4. Note that it is not necessary for the two CODPs to be positioned at the same place within the SA, they could be positioned separately due to e.g. the bill of material of the item provided by the SA. This would result in a partial misalignment with limited sense business wise but could still exist for technical reasons.

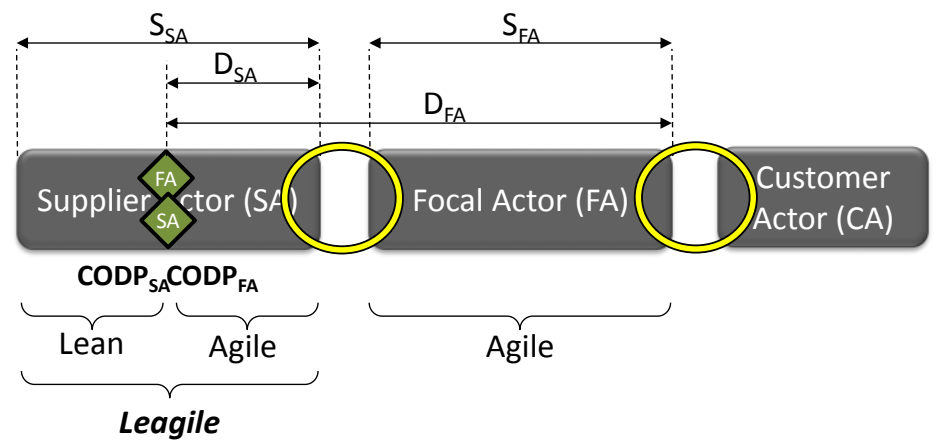

Fig. 4. Interface alignment 2: Flexibility-Flexibility

\subsection{Leagility in a triad: Interface misalignment 2}

The fourth configuration is based on Interface alignment 2 where the two CODPs were positioned at the same place within the SA. However, in this case, the SA is forecastdriven and hence the $\mathrm{CODP}_{\mathrm{SA}}$ is positioned at the end of $\mathrm{SA}$ (i.e. $\mathrm{D}_{\mathrm{SA}}=0$ ) as shown in Fig. 5. As a consequence, lean at the SA side is facing agile at the FA side resulting in a misalignment. Note that this could be the consequence of limited information sharing between the two supply actors since even though the FA has the delivery lead-time of $D_{\mathrm{FA}}$, where $\mathrm{S}_{\mathrm{FA}} \leq \mathrm{D}_{\mathrm{FA}}$, this information is not known by the $\mathrm{SA}$ which thus has selected a forecast-driven approach.

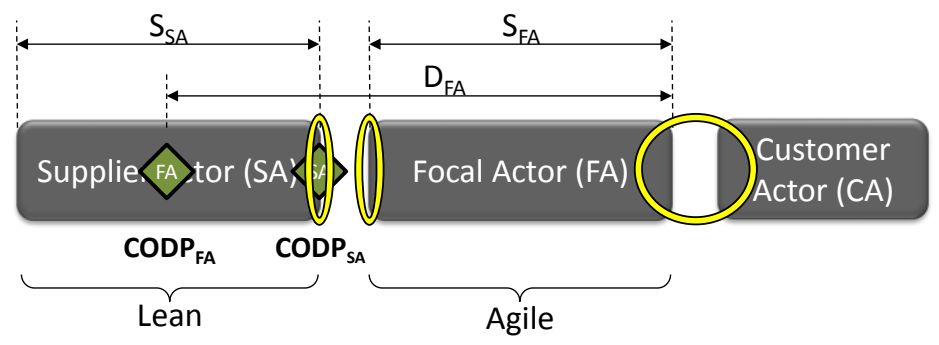

Fig. 5. Interface misalignment 2: Cost-Flexibility 


\section{Examples of the four interface configurations}

Table 1 provides a structured summary of the four configurations outlined above. The first column of Table 1 represent configurations where purchasing is based on forecast. The two cases in the second column represent configurations where purchasing is customer-order-driven. The first row represents delivery from finished goods inventory by the SA and the second row that the SA performs some customer-order-driven activities before the actual delivery is performed.

Table 1. Four interface configurations

\begin{tabular}{|c|c|c|c|}
\hline \multirow{3}{*}{$\begin{array}{l}\text { Supplier } \\
\text { actor (SA) }\end{array}$} & & \multicolumn{2}{|c|}{ Focal actor (FA) perspective } \\
\hline & & Cost $\left(S_{F A}>D_{F A}\right)$ & Flexibility $\left(S_{F A} \leq D_{F A}\right)$ \\
\hline & Cost (DsA=0) & Alignment 1 & Misalignment 2 \\
\hline perspective & Flexibility $\left(\mathrm{D}_{\mathrm{SA}}>0\right)$ & Misalignment 1 & Alignment 2 \\
\hline
\end{tabular}

The four interface configurations are exemplified by using empirical illustrations gathered from the case company Parker Hannifin AB in Trollhättan, Sweden (henceforth referred to as Parker). The empirical illustrations are based on a deeper case analysis presented in [4] and [14]. Parker is part of Parker Hannifin Corporation, which is a global leader in 'Motion and Control Technologies'. Parker manufactures heavy-duty hydraulic pumps and motors with fixed and variable displacement. The product family F12, in the fixed motors segment, is sold both as a standard product and as a customized product and is used to exemplify the four interface configurations in terms of four scenarios. Parker is acting as the FA in the examples below, and hence "Parker" is used instead of "FA" as the index. For the standard F12, the requested delivery lead-time

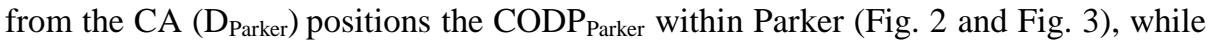

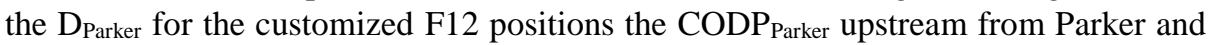
within the SA (Fig. 4 and Fig. 5).

Interface alignment 1 :

The F12 is assembled from 30 items and out of these items four are made in-house and 26 are purchased [4]. Out of all the purchased items 19 are purchased based on forecast (i.e. $S_{\text {Parker }}>D_{\text {Parker }}$ ) where 18 of them are made-to-stock by the $S A$ (i.e. $\mathrm{D}_{\mathrm{SA}}=0$ ). Roughly two thirds of all constituent items are thus related to Interface alignment 1.

Interface misalignment 1 :

In all Parkers fixed motors (including F12), the same type of Parker specific O-ring is included, regardless of product variant. The SA for these O-rings manufactures this item based on a customer order from Parker (i.e. $\mathrm{D}_{\mathrm{SA}}>0$ ). Parker on the other hand purchases the O-rings based on a forecast of future orders from the CA (i.e. $\mathrm{S}_{\text {Parker }}>\mathrm{D}_{\text {Par- }}$ ker). The $\mathrm{CODP}_{\mathrm{SA}}$ and $\mathrm{CODP}_{\text {Parker }}$ are thus positioned internally at the respective actor, corresponding to interface misalignment 1 . Hence, both the SA and Parker are performing the last activities based on customer order respectively. However, Parker identified this misalignment and later changed this scenario to alignment 1, by replacing the customized O-ring with a standard O-ring stocked by the SA. 
Interface alignment 2:

One of Parkers more strategic items, a shaft, is purchased and manufactured based on customer order from the CA (i.e. S $S_{\text {Parker }} \leq D_{\text {Parker }}$ ) as it is customized. The customization also affects the SA and, under the assumption that customization is not performed on speculation, the $\mathrm{CODP}_{\mathrm{SA}}$ and the $\mathrm{CODP}_{\text {Parker }}$ are positioned at the same place, i.e. inside the $\mathrm{SA}$ (i.e. $\mathrm{D}_{\mathrm{SA}}>0$ ). This scenario therefore corresponds to interface alignment 2 where the two decoupling points are positioned within the SA. Note that Parker is delivering to customer order from the CA and that SA is delivering based on customer order from Parker. Both these CODPs are however positioned at the same place in the triad.

Interface misalignment 2:

The conic roller bearings used in F12 are standard items for Parker since they are used for every F12 regardless of product variant. Parker purchases this item based on customer order from the CA, positioning the CODP Parker internally at the SA (i.e. S $\mathrm{S}_{\text {ar- }}$ ${ }_{k e r} \leq D_{\text {Parker }}$ ). However, the SA delivers this item from stock (i.e. $D_{S A}=0$ ), positioning the $\mathrm{CODP}_{\mathrm{SA}}$ at the end of the SA. Hence, the supply lead-time SParker is shorter than the delivery lead-time ( $D_{\text {Parker }}$ ) for F12. The SA could have manufactured this item based on a customer order from Parker but has decided to manufacture this item based on forecast. This scenario therefore corresponds to interface misalignment 2.

\section{Conclusions and further research}

Leagility is usually approached in a dyadic setting where the CA's requirements are considered (at FA) in terms of the requested delivery lead-time. By including a third actor (the SA), a triad perspective is obtained and as we have shown this leads to additional complexity due to the two actor-interfaces. The strategic lead-times S and D of the actors, and consequently the position of the CODPs, have a critical impact on how to balance cost with flexibility at the actor interfaces. The examples presented above point to that the two aligned interface strategies are preferable to the misaligned strategies, but a more detailed investigation of other cases will need to be performed to provide empirical support for the properties of the four identified interface configurations and on preferred transitions between the configurations. In this leagility context it would also be interesting to investigate the impact on financial performance. Furthermore, the theory needs to be extended to also cover a more detailed discussion on internal properties of the SA and FA and in particular how the CODPs can be positioned at different internal positions. Also the impact of different levels of customization in relation to the agile strategy needs to be analyzed.

\section{Acknowledgement}

This research has been performed in collaboration with six companies in the projects KOPeration and KOPtimera. The projects are funded by the Swedish Knowledge Foundation (KKS), Jönköping University and the participating companies. In particular the authors would like to express their gratitude to Parker Hannifin in Trollhättan, Sweden. 


\section{References}

[1] J. P. Womack and D. T. Jones, Lean thinking : banish waste and create wealth in your corporation. New York, NY: Simon \& Schuster, 1996.

[2] S. Goldman and K. Preiss, Eds., 21st century manufacturing enterprise strategy: An industry-led view. DIANE Publishing, 1991, p.^pp. Pages.

[3] B. Naylor, J., M. Naim, M., and D. Berry, "Leagility: Integrating the lean and agile manufacturing paradigms in the total supply chain," International Journal of Production Economics, vol. 62, pp. 107-118, 1999.

[4] J. Bäckstrand, "A Method for Customer-driven Purchasing : Aligning Supplier interaction and Customer-driven manufacturing," School of Engineering, Jönköping University, Jönköping, 2012.

[5] J. T. Mentzer, W. DeWitt, J. S. Keebler, S. Min, N. W. Nix, C. D. Smith, et al., "Defining supply chain management," Journal of Business logistics, vol. 22 , pp. 1-25, 2001.

[6] S. Hoekstra and J. Romme, Eds., Integral logistic structures: developing customer-oriented goods flow. New York: Industrial Press, 1992, p.^pp. Pages.

[7] P. M. J. Giesberts and L. van der Tang, "Dynamics of the customer order decoupling point: impact on information systems for production control," Production Planning \& Control, vol. 3, pp. 300-313, 1992.

[8] S. Shingō, Study of Toyota Production System from Industrial Engineering Viewpoint. Tokyo: Japan Management Association, 1981.

[9] H. Mather, "Attack your P: D ratio," in proceedings from the 1984 APICS Conference, 1984.

[10] J. Bäckstrand and J. Wikner, "Time-phasing and decoupling points as analytical tools for purchasing," in proceedings from the IEEE International Conference on Industrial Engineering and Engineering Management Bangkok, Thailand, 2013.

[11] J. Wikner, "On decoupling points and decoupling zones," Production \& Manufacturing Research, vol. 2, pp. 167-215, 2014.

[12] J. Wikner, "Supply Chain Management Strategies in Terms of Decoupling Points and Decoupling Zones," in Advances in Production Management Systems. Innovative and Knowledge-Based Production Management in a Global-Local World. vol. 438, B. Grabot, B. Vallespir, S. Gomes, A. Bouras, and D. Kiritsis, Eds., ed: Springer Berlin Heidelberg, 2014, pp. 371-378.

[13] X. Y. Sun, P. Ji, L. Y. Sun, and Y. L. Wang, "Positioning multiple decoupling points in a supply network," International Journal of Production Economics, vol. 113, pp. 943-956, 2008.

[14] E. Hedén and F. Tiedemann, "How to improve the inbound flow of a manufacturing company: Analyzing and refining the Customer-driven Purchasing method," Jönköping University, Jönköping, 2014. 